\title{
A Comparison of Schemas, Schema Modes and Childhood Traumas in Obsessive-Compulsive Disorder, Chronic Pain Disorder and Eating Disorders
}

\author{
Ulrich Voderholzer ${ }^{\mathrm{a}, \mathrm{c}}$ Caroline Schwartz ${ }^{\mathrm{d}}$ Nicola Thiel $^{\mathrm{a}}$ Anne Katrin Kuelz ${ }^{\mathrm{a}}$ \\ Armin Hartmann $^{b}$ Carl Eduard Scheidt ${ }^{\text {b Sandra Schlegl }}{ }^{d}$ Almut Zeeck $^{b}$ \\ ${ }^{a}$ Department of Psychiatry and Psychotherapy, University Medical Center and ${ }^{\mathrm{b}}$ Department of Psychosomatic \\ Medicine and Psychotherapy, University of Freiburg, Freiburg, 'Schoen Clinic Roseneck, Prien, and dDepartment of \\ Psychiatry and Psychotherapy, University Hospital (LMU), Munich, Germany
}

\section{Key Words}

Obsessive-compulsive disorder · Maladaptive schemas .

Childhood traumas

\begin{abstract}
Background: In this study, we investigated early maladaptive schemas (EMS), schema modes and childhood traumas in patients suffering from obsessive-compulsive disorder $(O C D)$ in contrast to patients with other Axis I disorders. Based on cognitive theories on OCD, our main research question was whether schemas belonging to the domain of 'impaired autonomy and performance' are more prevalent in OCD than in both eating disorders (ED) and chronic pain disorder (CPD). Sampling and Methods: EMS, schema modes and traumatic childhood experiences were measured in 60 patients with $O C D, 41$ with ED, 40 with CPD and 142 healthy controls. To analyze differences between the groups, MANCOVAs were conducted followed by deviation contrasts. Depression level, age and gender were considered as possible covariates. Results: OCD patients scored higher on 4 EMS, 2 of which belong to the domain 'impaired autonomy and performance'. ED patients had higher scores in the EMS 'emotional inhibition' and CPD pa-
\end{abstract}

tients on the Childhood Trauma Questionnaire subscale 'physical neglect'. Conclusions: These results suggest that there might be typical schema patterns associated with $O C D$ and ED. We can also conclude that a higher prevalence of traumatic experiences does not necessarily coincide with more EMS and schema modes.

Copyright $\odot 2013$ S. Karger AG, Base

\section{Introduction}

Cognitive and behavioral theories about obsessivecompulsive disorder (OCD) currently focus on the cognitions and behaviors related to this disorder. Cognitive patterns such as overestimating the probability of danger [1], a very high sense of responsibility and a tendency to fuse thoughts and reality [2] have been proposed, but few studies have addressed the roots of these patterns. To this end, the schema approach [3] which integrates the assumptions of psychodynamic, cognitive-behavioral and attachment theories might be useful. In this approach, schema comprises subjective constructs that contain a broad pattern of memories, emotions and cognitions which are relevant for social behavior. Schemas deter-

\section{KARGER}

E-Mail karger@karger.com

www.karger.com/psp
(C) 2013 S. Karger AG, Basel

0254-4962/14/0471-0024\$39.50/0
Prof. Ulrich Voderholzer

Schoen Clinic Roseneck

Am Roseneck 6

DE-83209 Prien am Chiemsee (Germany)

E-Mail UVoderholzer@ schoen-kliniken.de 
mine, in later life, how an individual perceives other individuals, the self and relations with others. In contrast to healthy schemas, maladaptive ones prevent individuals from obtaining valued goals, e.g. building lasting relationships. Maladaptive schemas are regarded as being a core concept for understanding personality disorders, and schema therapy aims at helping patients who do not respond to classical cognitive-behavioral therapy [4]. An early maladaptive schema (EMS) develops as a consequence of harmful relational experiences during childhood. Traumatic events and the violation of basic needs like safety, guidance and affection can be the source of these experiences. Schemas are postulated to be highly stable [4], i.e. their content and importance remain unchanged unless significant corrective experiences are made. The clinical schema approach postulates that EMS predispose individuals to vulnerability for psychiatric disorders. However, the same patient can show rather different behaviors in different situations and distinct schemas can be activated in parallel. The schema mode concept takes these observations into account [3]. A schema mode is defined as a cluster of several activated schemas and their associated cognitions and emotions [3]. In contrast to the more trait-related EMS, schema modes are state-dependent and are thus dynamic. So far, the schema mode concept has been only scantly investigated in Axis I disorders. Although the schema therapy approach is predominantly used for explaining and treating personality disorders (e.g. [5]), Young et al. [3] also hypothesized that EMS and schema modes are a crucial aspect of many Axis I disorders. With respect to OCD, EMS that can be grouped in the domain of 'impaired autonomy and performance' [3] could play an important role. EMS belonging to this domain are 'dependence', 'vulnerability' (to harm or illness), 'enmeshment'/'undeveloped self and 'failure'. These schemas can develop if the child's basic needs of autonomy and feeling competent are frustrated. It is plausible that in later life, EMS of this kind, in particular 'vulnerability', might pave the way for cognitive patterns that are typical for OCD, e.g. a high degree of vigilance regarding possible dangers [1].

To our knowledge, no comparative study on EMS or schema modes in OCD versus other disorders has been conducted so far. For the comparison, we chose eating disorders (ED) as this condition does not belong to the category of anxiety disorders but at the same time is closely related to OCD. High comorbidity rates of up to $17 \%$ [6] and conceptual considerations [7] account for this relation. On the other hand, we chose a clinical comparison group that shows lower but still existing comorbidity rates. Chronic pain disorder (CPD; comorbidity 3.7\% [6]) fulfils this condition. Although there is a lack of comparisons between different Axis I disorders, a study on EMS in OCD versus healthy controls does exist [8], as well as comparisons of ED [9] and CPD [10] samples with controls. These studies found higher levels of EMS in clinical samples. So far, no study has investigated the more state-related concept of schema modes in ED, nor in OCD and CPD.

In the schema therapy approach, early childhood traumas are regarded as a crucial etiological factor for the development of EMS. Thus, trauma can be regarded as a more basic concept than EMS even though there is a conceptual overlap, e.g. between the scale 'emotional neglect' of the Childhood Trauma Questionnaire (CTQ) [11] and the EMS 'emotional deprivation' [3]. Traumatic events are also known to be risk factors for later ED [12] and CPD [13]. Traumatic experiences may also contribute to the development of OCD, but have to be considered together with biological predisposition, vulnerability and other stressors [14]. As is the case for EMS, the literature does not reveal clear relationships between certain kinds of traumatic experience and specific disorders.

In this study, we investigated whether there are EMS, schema modes and traumatic experiences in childhood that are associated in a stronger way with OCD than with other Axis I disorders, namely ED and CPD. With regard to EMS, our main research question was whether or not there are significantly higher levels of 'dependence', 'vulnerability', 'enmeshment' and 'failure' in OCD. We also included a healthy control group in our analysis to compare control subjects with all patients. We expected that, in this analysis, the general psychopathology of the clinical group would yield significant differences in all measurements of schema and trauma.

\section{Methods}

Sample

Data for this study was collected in 4 different German centers: OCD at the Department of Psychiatry and Psychotherapy and ED and CPD at the Department of Psychosomatic Medicine and Psychotherapy of the University Hospital of Freiburg, CPD and ED at the Thure-von-Uexkuell-Klinik for Psychosomatic Medicine and Psychotherapy, Freiburg and OCD at the Schoen Clinic Roseneck, Prien. These hospitals were chosen for recruitment as they have specialized units for the respective disorders. All diagnoses were made by trained clinicians using the SCID interview based on DSM-IV criteria. The same clinician conducted each structured interview. In case of unclear responses to an item, the diagnoses were confirmed by another experienced clinician. 
Patients were not matched for age, gender or education level. Control subjects were matched to clinical subjects with regard to age and gender. EMS are considered to develop early in childhood and to be rather resistant to change unless worked on in a special therapy. Moreover, the disorders we examined differ substantially in their age and sex prevalences so that matching would not have been possible. Depression was assessed using the Beck Depression Inventory II (BDI-II [15], German version [16]). Inclusion criteria for the study were: diagnosis of OCD, ED or CPD according to the DSM-IV criteria as assessed by the structured interview, age between 18 and 65 years and written informed consent. Patients were excluded from participation in the case of an acute or past psychotic episode, severe neurological disorder and/or severe cognitive deficits. In addition, if a patient had a comorbid diagnosis of one of the comparison groups (for example an OCD patient with comorbid ED), this patient was excluded from the study.

Sixty patients with primary OCD (mean age $35.9 \pm 10.9$ years), 41 with $\mathrm{ED}$ (mean age $24.3 \pm 7.2$ ), 40 with CPD (mean age $47.0 \pm$ 11.2 ) and 142 healthy controls (mean age $35.5 \pm 13.8$ ) participated in this study. Recruitment of controls was conducted via advertisement or personal contacts. All participants received an allowance of EUR 20. The OCD sample consisted of 34 female and 26 male participants, the ED sample included only females, 27 women and 13 men made up the CPD sample and the control subjects consisted of 102 female and 40 male subjects.

\section{Measures}

To control for sequence effects, all questionnaires were administered in a randomized order. To assess the presence of EMS we employed the Young Schema Questionnaire (YSQ-S3) consisting of 90 items [17] (German version [18]; online suppl. table 1; for all online supplementary material, see www. karger.com/doi/10.1159/000348484). Eighteen schemas are measured using a 6-point Likert-type scale. Each schema is represented with 5 items and the average value ranging from 1 to 6 is used to assess how pronounced the schema is. Higher values indicate more pronounced schemas. The YSQ-S3 is widely used in clinical practice as well as research [e.g. 19]. Kriston et al. [20] studied the psychometric quality of the German version and confirmed its reliability and validity.

In addition, the Schema Mode Inventory - revised version (SMIr), a 124-item questionnaire, served to measure schema modes. The SMIr covers 14 modes (online suppl. table 2). Average values are used to assess an individual's schema modes. Lobbestael et al. [21] found a high internal consistency and discriminant validity as well as a very good retest reliability (mean ICC $=0.84$ ). Similar results were found for the German version [22].

The short version of the CTQ (31 items with a 5-point Likerttype scale) was administered to assess the presence of traumatic experiences during childhood and youth [11] (German version [23]). The CTQ measures 5 potential domains: 'emotional abuse', 'physical abuse', 'sexual abuse', emotional neglect and 'physical neglect'. For the German version, the factor structure, good reliability and validity were demonstrated [24]. So far, norms for the German version do not exist. In our study we therefore entered the raw scores in our comparative analyses.

As the existing literature hints at a potential confounding influence of comorbid depression, we also assessed the level of depression using the Beck Depression Inventory as mentioned above. Moreover, we made use of an additional disorder-specific measure for each of the disorders investigated: the Obsessive Compulsive Inventory-Revised (OCI-R; 18 items [25], German version [26]) and the Yale-Brown Obsessive Compulsive Scale (Y-BOCS [27], German version [28]) for patients with OCD, the Eating Disorder Inventory 2 (EDI-2; 64 items [29], German version [30]) for ED and the Screening for Somatoform Disorders (SOMS; 68 items [31]) for CPD.

\section{Data Analysis}

As a first step, we conducted 3 MANOVAs: with the 18 maladaptive schemas, with the 14 schema modes and with the 5 main CTQ subscales as dependent variables (37 variables). Group, i.e. psychopathological group (OCD, ED and CPD patients combined) versus control group, was the independent variable in these analyses. The main effects were considered significant at $\mathrm{p}<0.001$ ( $\mathrm{p}=0.05$ divided by 37 , i.e. the number of dependent variables).

The second step was to compare the patient groups to each other, using MANCOVAs. Patient group (OCD vs. ED vs. CPD) was the independent variable and the scales of the YSQ, the SMIr and the CTQ served as dependent variables. Depression level (BDI-II score), gender and age were considered as covariates in these analyses. Results were only adjusted for the covariates if they were significantly associated with the dependent variables.

In addition, deviation contrasts were used to further analyze differences between the patient groups. More concretely, we were interested in whether each patient group differed from the 2 others with respect to the dependent variables (schema, schema modes and traumas). For alpha error correction, the false discovery rate [32] was applied as it provides greater power than the Bonferroni correction. For the 37 dependent variables (18 EMS scales, 13 SMIr and 5 CTQ scales), this meant that results were significant if the alpha level is $\mathrm{p}<0.0119$. This alpha level was also used in the following analyses.

\section{Results}

\section{Patients versus Control Group}

YSQ. As expected, the MANOVA yielded significant differences on all dependent variables between patients and nonpatients (all $\mathrm{p}<0.001$ ), except for the subscale 'entitlement' ( $p=0.026, \eta^{2}=0.018$; online suppl. table 3 ).

SMI. For the schema mode 'impulsive child' $(\mathrm{p}=0.866$, $\left.\eta^{2} \leq 0.001\right)$, 'bully and attack mode' $\left(p=0.016, \eta^{2}=0.021\right)$ and 'self-aggrandizer' ( $\left.p=0.002, \eta^{2}=0.033\right)$ the difference between patients and controls was not significant. For all other schema modes the differences were significant ( $\mathrm{p}<0.001$; online suppl. table 4 ).

CTQ. Patients and controls differed significantly on all five subscales ( $\mathrm{p}<0.001$; online suppl. table 5 ).

\section{Patients among Each Other}

YSQ. All possible covariates were significantly associated with the dependent variables [depression level (BDI) $\mathrm{p}<0.001$, gender $\mathrm{p}=0.045$, age $\mathrm{p}=0.011]$. Therefore, the 
Table 1. YSQ scales in OCD, ED and CPD patients and results of deviation contrasts

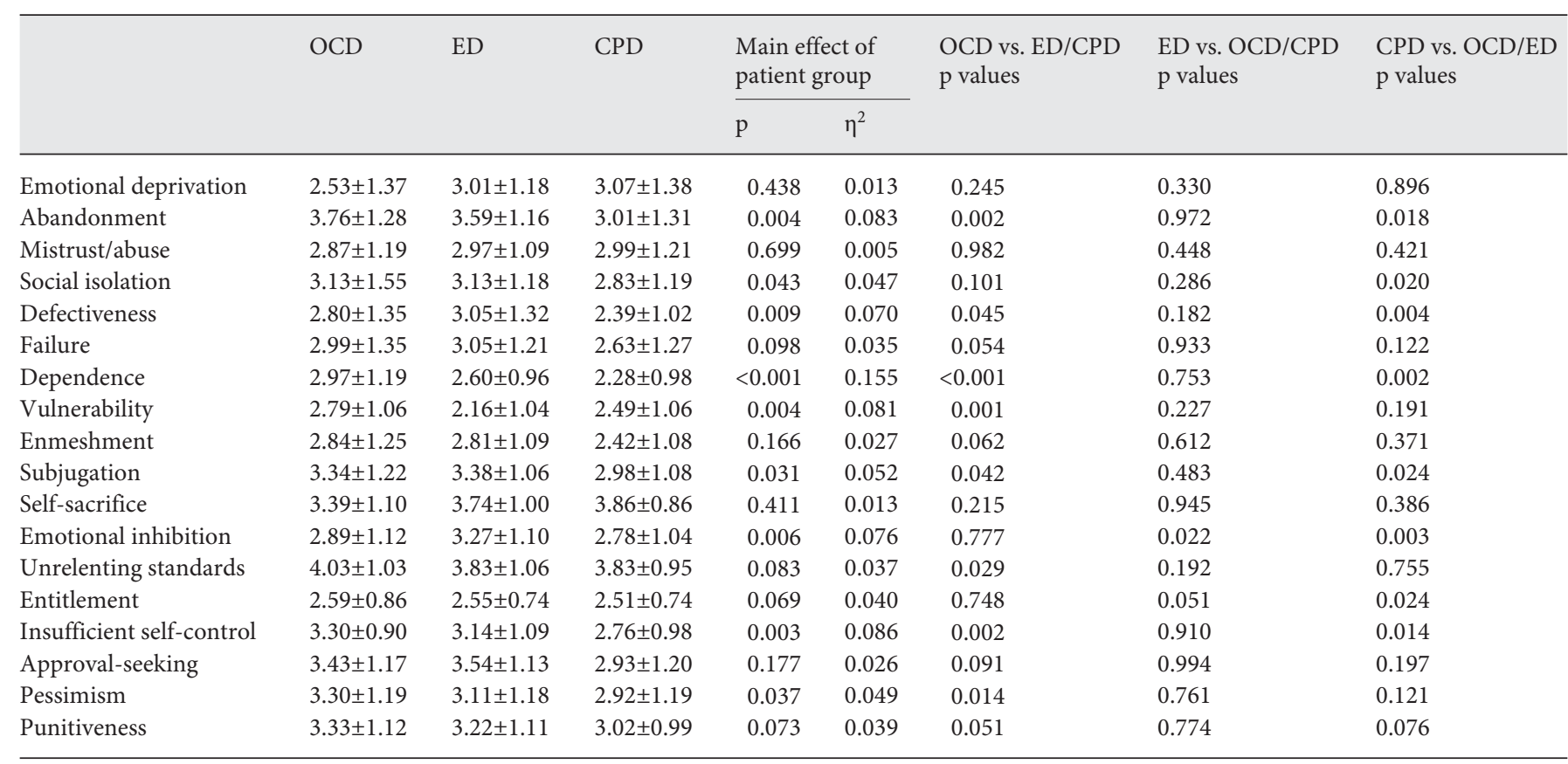

Means and standard deviations (SD).

results were adjusted for these 3 variables. The MANCOVA showed a significant main effect of patient group on the schemas 'abandonment', 'defectiveness', dependence, vulnerability, 'emotional inhibition' and 'insufficient selfcontrol'. For means, standard deviations, and all main effects of the patient group, see table 1 .

$O C D$ versus $E D / C P D$. OCD patients had significantly higher scores than the 2 other disorders on the schemas 'abandonment' ( $\mathrm{p}=0.002)$, 'dependence' $(\mathrm{p}<0.001)$, 'vulnerability' ( $\mathrm{p}=0.001)$ and 'insufficient self-control' $(\mathrm{p}=0.002)$. For complete results of the deviation contrasts, see table 1 and online suppl. figure 1 .

$E D$ versus $O C D / C P D$. ED patients scored significantly higher on the schema 'emotional inhibition' $(\mathrm{p}=0.002)$.

$C P D$ versus $O C D / E D$. CPD patients had significantly lower scores on 'defectiveness' ( $\mathrm{p}=0.004)$, 'dependence' $(\mathrm{p}=0.002)$ and 'emotional inhibition' $(\mathrm{p}=0.003)$.

$S M I$. Concerning schema modes, only the covariate depression level (BDI) had a significant association $(\mathrm{p}<0.001)$. Age $(\mathrm{p}=0.139)$ and gender $(\mathrm{p}=0.080)$ were therefore excluded. Results are only adjusted for the BDI. The main effect of the patient group was significant for the schema modes 'vulnerable child', 'angry child', 'detached protector', 'detached self-soother', 'punishing par- ent' and 'demanding parent'. See table 2 for means, standard deviations and all main effects of the patient group.

$O C D$ versus $E D / C P D$. Deviation contrasts showed that OCD patients had significantly higher scores on the schema modes 'vulnerable child' $(\mathrm{p}=0.002)$, 'angry child' $(\mathrm{p}=0.003)$, 'punishing parent' $(\mathrm{p}=0.007)$ and 'demanding parent' ( $p<0.001)$. For complete results of all deviation contrasts, see table 2 and online suppl. figure 2 .

$E D$ versus $O C D / E D$. ED patients scored significantly higher on the schema modes 'detached protector' $(\mathrm{p}=0.007)$ and 'detached self-soother' $(\mathrm{p}=0.001)$.

$C P D$ versus $O C D / E D$. CPD patients had lower scores on the following dependent variables: 'vulnerable child' $(\mathrm{p}=0.003)$, 'detached protector' $(\mathrm{p}=0.006)$, 'detached self-soother' ( $p=0.002)$, 'punishing parent' $(p=0.002)$ and 'demanding parent' ( $\mathrm{p}=0.009)$.

\section{CTQ}

BDI $(\mathrm{p}=0.006)$ and gender $(\mathrm{p}=0.001)$ were significantly associated with the CTQ scales whereas age $(\mathrm{p}=0.088)$ was not, so that results are adjusted for BDI and gender. The main effect of the patient group was only significant for 'physical neglect' (see table 3). 
Table 2. SMIr scales in OCD, ED and CPD patients

\begin{tabular}{|c|c|c|c|c|c|c|c|c|}
\hline & \multirow[t]{2}{*}{ OCD } & \multirow[t]{2}{*}{ ED } & \multirow[t]{2}{*}{ CPD } & \multicolumn{2}{|c|}{$\begin{array}{l}\text { Main effect of } \\
\text { patient group }\end{array}$} & \multirow[t]{2}{*}{$\begin{array}{l}\text { OCD vs. ED/CPD } \\
\text { p values }\end{array}$} & \multirow[t]{2}{*}{$\begin{array}{l}\mathrm{ED} \text { vs. } \mathrm{CD} / \mathrm{CPD} \\
\mathrm{p} \text { values }\end{array}$} & \multirow[t]{2}{*}{$\begin{array}{l}\mathrm{CPD} \text { vs. } \mathrm{CD} / \mathrm{ED} \\
\mathrm{p} \text { values }\end{array}$} \\
\hline & & & & $\mathrm{p}$ & $\eta^{2}$ & & & \\
\hline Vulnerable child & $3.19 \pm 1.21$ & $3.06 \pm 0.96$ & $2.90 \pm 1.14$ & 0.002 & 0.094 & 0.002 & 0.856 & 0.003 \\
\hline Angry child & $2.92 \pm 0.93$ & $2.56 \pm 0.77$ & $2.70 \pm 0.75$ & 0.011 & 0.066 & 0.003 & 0.105 & 0.263 \\
\hline Enraged child & $1.46 \pm 0.53$ & $1.40 \pm 0.45$ & $1.37 \pm 0.61$ & 0.411 & 0.014 & 0.229 & 0.957 & 0.295 \\
\hline Impulsive child & $2.31 \pm 0.73$ & $2.36 \pm 0.71$ & $2.42 \pm 0.62$ & 0.987 & $<0.001$ & 0.874 & 0.964 & 0.920 \\
\hline Undisciplined child & $2.68 \pm 0.72$ & $2.69 \pm 0.67$ & $2.56 \pm 0.76$ & 0.224 & 0.023 & 0.239 & 0.567 & 0.098 \\
\hline Happy child & $3.33 \pm 1.09$ & $3.12 \pm 0.92$ & $3.24 \pm 1.04$ & 0.207 & 0.024 & 0.561 & 0.225 & 0.079 \\
\hline Compliant child & $3.57 \pm 0.92$ & $3.49 \pm 0.87$ & $3.24 \pm 0.74$ & 0.023 & 0.057 & 0.036 & 0.544 & 0.011 \\
\hline Detached protector & $2.40 \pm 1.03$ & $2.79 \pm 1.00$ & $2.40 \pm 0.72$ & 0.010 & 0.069 & 0.977 & 0.007 & 0.006 \\
\hline Detached self-soother & $3.26 \pm 1.12$ & $3.82 \pm 1.12$ & $3.05 \pm 0.87$ & 0.002 & 0.093 & 0.702 & 0.001 & 0.002 \\
\hline Self-aggrandizer & $2.58 \pm 0.76$ & $2.46 \pm 0.75$ & $2.22 \pm 0.59$ & 0.042 & 0.048 & 0.046 & 0.658 & 0.023 \\
\hline Bully and attack mode & $1.74 \pm 0.63$ & $1.70 \pm 0.55$ & $1.79 \pm 0.65$ & 0.870 & 0.002 & 0.668 & 0.638 & 0.933 \\
\hline Punishing parent & $2.47 \pm 1.05$ & $2.39 \pm 0.88$ & $2.15 \pm 1.01$ & 0.003 & 0.084 & 0.007 & 0.573 & 0.002 \\
\hline Demanding parent & $4.26 \pm 1.03$ & $3.79 \pm 0.88$ & $3.67 \pm 0.86$ & $<0.001$ & 0.111 & $<0.001$ & 0.357 & 0.009 \\
\hline Healthy adult & $3.99 \pm 0.96$ & $3.78 \pm 0.82$ & $3.94 \pm 0.81$ & 0.306 & 0.018 & 0.913 & 0.192 & 0.155 \\
\hline
\end{tabular}

Means and standard deviations (SD).

Table 3. CTQ scales in OCD, ED and CPD patients

\begin{tabular}{|c|c|c|c|c|c|c|c|c|}
\hline & \multirow[t]{2}{*}{ OCD } & \multirow[t]{2}{*}{$\mathrm{ED}$} & \multirow[t]{2}{*}{$\mathrm{CPD}$} & \multicolumn{2}{|c|}{$\begin{array}{l}\text { Main effect of } \\
\text { patient group }\end{array}$} & \multirow[t]{2}{*}{$\begin{array}{l}\text { OCD vs. ED/CPD } \\
\text { p values }\end{array}$} & \multirow[t]{2}{*}{$\begin{array}{l}\mathrm{ED} \text { vs. } \mathrm{OCD} / \mathrm{CPD} \\
\mathrm{p} \text { values }\end{array}$} & \multirow[t]{2}{*}{$\begin{array}{l}\mathrm{CPD} \text { vs. } \mathrm{OCD} / \mathrm{ED} \\
\mathrm{p} \text { values }\end{array}$} \\
\hline & & & & $\mathrm{p}$ & $\eta^{2}$ & & & \\
\hline Emotional abuse & $9.74 \pm 5.44$ & $10.22 \pm 4.45$ & $12.46 \pm 7.17$ & 0.173 & 0.026 & 0.757 & 0.074 & 0.030 \\
\hline Physical abuse & $6.47 \pm 3.51$ & $6.88 \pm 3.94$ & $9.46 \pm 6.41$ & 0.018 & 0.059 & 0.058 & 0.418 & 0.009 \\
\hline Sexual abuse & $5.86 \pm 2.64$ & $7.27 \pm 4.72$ & $6.33 \pm 3.23$ & 0.203 & 0.024 & 0.333 & 0.214 & 0.694 \\
\hline
\end{tabular}

Means and standard deviations (SD).

Deviation contrasts showed that CPD patients had higher scores on 'physical neglect' than OCD and ED patients $(p=0.001)$. For complete results, see table 3 and online suppl. figure 3.

\section{Discussion}

Firstly, we found that the clinical group consisting of OCD, ED and CPD patients could be clearly differentiated from age- and gender-matched nonpatients by the level of most EMS and schema modes and by all childhood traumas. Interestingly, we did not find differences between the clinical and the control group on the EMS 'entitlement' nor on the schema modes 'self-aggrandizer', 'bully and attack mode' and 'impulsive child'. Possibly, these 3 schema modes go along with a certain degree of self-assurance and self-esteem that, in turn, is correlated with psychic health. To further strengthen this, our findings need to be replicated with a differently composed patient group.

Our initial research question whether or not there are more pronounced impaired 'autonomy and performance' EMS in OCD can be partially affirmed. OCD patients scored significantly higher than ED and CPD patients on 2 EMS belonging to this domain, namely, 'dependence' 
and 'vulnerability'. These 2 EMS contain the notions of being incompetent in handling everyday life and of not being safe. High scores on these EMS might pave the way for the development of cognitive patterns typically found in OCD, for instance, an exaggerated sense of responsibility for harmful events [2]. Our finding of higher 'vulnerability' scores in OCD is supported by the study of Atalay et al. [8]. They had found higher scores on this EMS in OCD compared to controls but did not examine whether certain EMS are typical for OCD by comparing them to other clinical groups. Lawson et al. [33] investigated ED patients who also suffered from OCD symptoms. They found that compulsive behaviors were associated with the EMS 'dependence' (among others). In our study, we explicitly excluded OCD patients with an ED comorbidity, and vice versa, so we cannot directly compare our results to those of Lawson et al. [33]. However, our interpretation that high scores on 'dependence' might increase the vulnerability for OCD symptoms is supported by their results.

Difficulties in the domain impaired autonomy and performance' also fit well with psychoanalytical concepts of OCD. From this point of view, OCD patients have contradictory representations of self and others, leading to a high ambivalence between love and acceptance on the one hand, and hate, criticism and rejection on the other [34]. The representations derive from early relationship experiences like those described by the domain of 'impaired autonomy and performance'.

OCD patients did not have higher 'enmeshment' and 'failure' scores than ED and CPD patients. Possibly, even though belonging to the same domain, only the EMS 'dependence' and 'vulnerability' are associated with OCD typical cognitive patterns, whereas 'failure' could, for example, be more associated with depression (which was a covariate in our study) or other disorders.

In our study, we found 2 other EMS being more pronounced in OCD patients than in ED and CPD: 'abandonment' and 'insufficient self-control'. Recently, Haaland et al. [35] examined EMS as predictors of treatment outcome. They found that OCD patients with high scores on the 'abandonment' schema benefit less from a standard cognitive-behavioral therapy. This indicates that knowledge of schema patterns might also help in predicting therapy outcome, and, in a further step, improve therapy for patients with certain schema patterns. The EMS 'insufficient self-control' belongs to the domain 'overvigilance and inhibition' [3]. With regard to this EMS, the basic feeling of not being in control might be overcompensated by the development of OCD symptoms like ex- cessive checking. It is therefore plausible that the EMS insufficient self-control is associated with OCD.

The comparison of OCD with the 2 other disorder groups also revealed higher scores on the schema modes 'vulnerable child', 'angry child', 'punishing parent' and 'demanding parent'. Schema modes are more difficult to interpret since they are supposed to be less stable and therefore reflect more a current state than a trait. Nevertheless, these maladaptive child and parent modes match with the EMS on which OCD patients had higher scores. Our findings suggest that the activation of maladaptive child and parent modes is particularly pronounced in OCD, which should be considered in therapy planning.

In our study, we found 1 EMS on which ED scored higher than in OCD and CPD patients: 'emotional inhibition'. This EMS shows similarities with findings based on other theoretical models or empirical research that stress the role of avoidance behaviors in ED [36]. Moreover, we found the maladaptive coping modes 'detached protector' and 'detached self-soother' to be more pronounced in ED than in OCD and CPD. It is interesting that in our ED sample, the maladaptive coping modes were significantly higher whereas OCD patients scored higher on maladaptive child and parent modes. This hints at a particular importance of coping modes in the treatment of ED and current emotional states in OCD.

While CPD patients had less pronounced EMS and schema modes, they scored higher on the subscale 'physical neglect' of the CTQ than both OCD and ED patients. Traumatic experiences are known to be a crucial factor in the development of somatoform disorders [13] and traumas that are anchored at the physical level seem to be of particular importance when directly compared to OCD and $\mathrm{ED}$. In conclusion, our findings suggest that schema and trauma should be regarded as different concepts by both researchers and practitioners. Even though they are related, one should not draw hasty conclusions about their empirical coexistence in a given patient group.

Cognitive behavioral therapy has proved to yield good effects in the treatment of OCD and ED [e.g. 37, 38] but does not work for all patients and relapse rates are rather high [e.g. 39, 40]. It has already been shown that schema therapy can yield good results in OCD patients who do not respond to standard therapy [41]. Our results may give important input for the development of specific schema therapy approaches for OCD and ED. Of course, we have to bear in mind that even if typical patterns in specific disorders exist, one still needs to check each individual's actual schemas before applying a certain approach. 
The schema concept could also build a bridge between cognitive-behavioral and psychodynamic approaches, which, per se, have a strong focus on the effects of early relationship experiences. A comparison of results on EMS and schema modes according to Young [3] and assessments by the Operationalized Psychodynamic Diagnostic-System [42] which operationalizes psychodynamic constructs like dysfunctional interpersonal patterns and central conflicts, could be a further step.

\section{Limitations}

At this point, we do not know whether schemas or symptoms come first in psychological development. Alternatively, maladaptive schemas may well be an epiphenomenon of a specific disorder. It is also important to note that maladaptive schemas may be typical but probably not specific to different mental disorders.

An important limitation of this study is the exclusive use of self-report measures. Our finding of less-pronounced maladaptive schemas and schema modes in CPD might be due to the tendency of these patients to hide their real mental condition and their strong need to appear 'normal' or only physically impaired. Deficits in experiencing and reflecting on emotions might also have added to this finding. Moreover, self-report measures only permit recording the conscious aspects of schemas, schema modes and traumas. Further possible difficulties with this kind of measurement are strategic reporting, response styles, feelings of shame, etc. Other studies, for example [5], hint at an underreporting of vulnerable child modes in disorders with overcompensation. Although the degree of overcompensation is difficult to measure, future studies could try to consider this as a possible confounding variable. Another limitation of this study is that not all possible influencing variables were controlled for. For example, the extent of former psychotherapy or pharmacotherapy may vary among patients. Also, our OCD sample was larger than the other samples, which might have resulted in reduced variance in this group and augmented variance in the other groups. Lastly, further studies should follow a longitudinal design as the cross-sectional design of our study imposes limitations on the conclusions that can be drawn.

\section{References}

1 Foa EB, Kozak MJ: Emotional processing of fear: exposure to corrective information. Psychol Bull 1986;99:20-35.

2 Veale D: Cognitive-behavioural therapy for obsessive-compulsive disorder. Adv Psychiatr Treat 2007;13:438-446.

3 Young JE, Klosko JS, Weishaar ME: Schema Therapy: A Practitioner's Guide. New York, Guilford, 2003.

4 Young JE: Cognitive Therapy for Personality Disorders: A Schema-Focused Approach, ed 3. Sarasota, Professional Resource Exchange, 1999.

5 Bamelis LL, Renner F, Heidkamp D, Arntz A: Extended schema mode conceptualizations for specific personality disorders: an empirical study. J Pers Disord 2011;25:41-58.

-6 Zaudig M: Heterogenität und Komorbidität der Zwangsstörung. Der Nervenarzt 2011;82: 290.

7 Hollander E: Obsessive-compulsive disorder: the hidden epidemic. J Clin Psychiatry 1997; 58:3-6.

8 Atalay H, Atalay F, Karahan D, Çaliskan M: Early maladaptive schemas activated in patients with obsessive compulsive disorder: a cross-sectional study. Int J Psychiat Clin 2008; $12: 268-279$ $\checkmark 9$ Cooper MJ, Rose KS, Turner H: Core beliefs and the presence or absence of eating disorder symptoms and depressive symptoms in adolescent girls. Int J Eat Disord 2005;38:6064.

10 Saariaho T, Saariaho A, Karila I, Joukamaa M: Early maladaptive schema factors, chronic pain and depressiveness: a study with 271 chronic pain patients and 331 control participants. Clin Psychol Psychother 2012;19:214223.

-11 Bernstein DP, Stein JA, Newcomb MD, Walker E, Pogge D, Ahluvalia T, Stokes J, Handelsman L, Medrano M, Desmond D, Zule W: Development and validation of a brief screening version of the childhood trauma questionnaire. Child Abuse Neglect 2003;27:169-190.

12 Brewerton TD: Eating disorders, trauma, and comorbidity: focus on PTSD. Eat Disord J Treat Prev 2007;15:285-304.

13 Sack M, Lahmann C, Jaeger B, Henningsen P: Trauma prevalence and somatoform symptoms: are there specific somatoform symptoms related to traumatic experiences? J Nerv Ment Dis 2007;195:928-933.

14 Maier S, Kuelz AK, Voderholzer U: Traumatisierung und Dissoziationsneigung bei Zwangserkrankten: ein Überblick. Verhaltenstherapie 2009;19:219-227.
15 Beck AT, Steer RA, Brown GK: Manual for the Beck Depression Inventory-II. San Antonio, Psychological Corporation, 1996.

16 Hautzinger M, Keller F, Kühner C: BDI-II. Beck Depressions-Inventar (Revision). Frankfurt, Harcourt Test Services, 2006.

17 Young JE: Young Schema Questionnaire (YSQ-S3). Eckerförde, Institiut für Schematherapie, 2006

18 Berbalk H, Grutschpalk J, Parfy E, Zarbock G: Young Schema Questionnaire (YSQ-S3). Eckernförde, Institut für Schematherapie, 2006.

19 Oei TPS, Baranoff J: Young Schema Questionnaire: review of psychometric and measurement issues. Aust J Psychol 2007;59:78-86.

20 Kriston L, Schafer J, von Wolff A, Harter M, Holzel LP: The latent factor structure of Young's early maladaptive schemas: are schemas organized into domains? J Clin Psychol 2012;68:684-698.

21 Lobbestael J, van Vreeswijk M, Spinhoven P, Schouten E, Arntz A: Reliability and validity of the short Schema Mode Inventory (SMI). Behav Cogn Psychother 2010;38:437-458.

22 Reiss N, Dominiak P, Harris D, Knörnschild C, Schouten E, Jacob G: Reliability and validity of the German version of the Schema Mode Inventory. Eur J Psychol Assess 2012;28:297-304. 
23 Bader K, Hänny C, Schäfer V, Neuckel A, Kuhl C: Childhood Trauma Questionnaire - psychometrische Eigenschaften einer deutschsprachigen Version. Z Klin Psychol Psychother 2009;38:223-230.

24 Wingenfeld KSC, Mensebach C, Grabe HJ, Hill A, Gast U, Schlosser N, Höpp H, Beblo T, Driessen M: The German version of the Childhood Trauma Questionnaire (CTQ): preliminary psychometric properties. Psychother Psychosom Med Psychol 2010;60:442-450.

25 Foa EB, Huppert JD, Leiberg S, Langner R, Kichic R, Hajcak G, Salkovskis PM: The Obsessive-Compulsive Inventory: development and validation of a short version. Psychol Assess 2002;14:485-496.

26 Gönner S, Ecker W, Leonhart R: ObsessiveCompulsive Inventory - revised (OCI-r). Deutsche adaptation. Manual. Frankfurt am Main, Pearson Assessment \& Information, 2009.

27 Goodman WK, Prince LH, Rasmussen SA Mazure C, Delgado P, Heninger GR, Charney DS: The Yale-Brown Obsessive Compulsive Scale. Arch Gen Psychiatry 1989;46:10061016.

28 Hand I, Büttner-Westphal H: The YaleBrown Obsessive Compulsive Scale (YBOCS): ein halbstrukturiertes Interview zur Beurteilung des Schweregrades von Denkund Handlungszwängen. Verhaltenstherapie 1991;1:223-225.
29 Garner DM: Eating Disorder Inventory-2: professional manual. Odessa, Psychological Assessment Resources, 1991.

30 Paul T, Thiel A: Eating Disorder Inventory - 2. Deutsche version. Göttingen, Hogrefe, 2004.

31 Rief W, Hiller W, Heuser J: SOMS - Screening für somatoforme Störungen. Manual zum Fragebogen. Bern, Verlag Hans Huber, 1997.

32 Narum S: Beyond Bonferroni: less conservative analyses for conservation genetics. Conserv Genet 2006;7:811-811.

33 Lawson R, Waller G, Lockwood R: Cognitive content and process in eating-disordered patients with obsessive-compulsive features. Eat Behav 2007;8:305-310.

34 Kempke S, Luyten P: Psychodynamics and cognitive-behavioral approaches of obsessive-compulsive disorder: is it time to work through our ambivalence? Bull Menninger Clin 2007;71:291-308.

35 Haaland AT, Vogel PA, Launes G, Haaland VØ, Hansen B, Solem S, Himle JA: The role of early maladaptive schemas in predicting exposure and response prevention outcome for obsessive-compulsive disorder. Behav Res Ther 2011;49:781-788.

36 Cassin SE, von Ranson KM: Personality and eating disorders: a decade in review. Clin Psychol Rev 2005;25:895-916.
37 Rosa-Alcázar AI, Sánchez-Meca J, GómezConesa A, Marín-Martínez F: Psychological treatment of obsessive-compulsive disorder: a meta-analysis. Clin Psychol Rev 2008;28: 1310-1325.

38 Steinhausen $\mathrm{H}-\mathrm{C}$, Weber S: The outcome of bulimia nervosa: findings from one-quarter century of research. Am J Psychiatry 2009; 166:1331-1341.

39 Lakatos A, Reinecker H: Kognitive Verhaltenstherapie bei Zwangsstörungen. Ein Therapiemanual. Manual (revision 3). Göttingen, Hogrefe, 2007.

40 Steketee G, Pigott TA: Obsessive compulsive disorder: the latest assessment and treatment strategies, ed 3. Kansas City, Compact Clinicals, 2006.

41 Sookman D, Steketee G: Specialized cognitive behavior therapy for treatment-resistant obsessive compulsive disorder; in Sookman D, Leahy RL (eds): Treatment-Resistant Anxiety Disorders: Resolving Impasses to Symptom Remission. New York, Routledge/Taylor \& Francis Group, 2010, pp 31-74.

42 Cierpka MGT, Rudolf G, von der Tann M, Staschf M: The operationalized psychodynamic diagnostics system: clinical relevance, reliability and validity. Psychopathology 2007;40:209-220. 